\title{
PREVISÃO DE DIÂMETROS AO LONGO DO FUSTE DE EUCALIPTO VIA REDES NEURAIS ARTIFICIAIS
}

Nathalia de Paiva Mendonça1, Mônica Canaan Carvalho², Lucas Rezende Gomide³, Antônio Carlos Ferraz Filho ${ }^{4}$, Matheus Andrade Ferreira ${ }^{5}$

${ }^{1}$ Engenheira Florestal, UFLA, Universidade Federal de Lavras, Departamento de Ciências Florestais DCF / UFLA (nathalia.p.mendonca@hotmail.com) Lavras-Brasil

${ }^{2}$ Engenheira Florestal, Mestre em Engenharia Florestal, UFLA, Universidade Federal de Lavras, Departamento de Ciências Florestais DCF / UFLA Lavras-Brasil

${ }^{3}$ Engenheiro Florestal, Doutor em Engenharia Florestal, UFLA, Universidade Federal de Lavras, Departamento de Ciências Florestais DCF / UFLA Lavras-Brasil

${ }^{4}$ Engenheiro Florestal, Doutor em Engenharia Florestal, UFLA, Universidade Federal de Lavras, Departamento de Ciências Florestais DCF / UFLA Lavras-Brasil

${ }^{5}$ Engenheiro Florestal, UFLA, Universidade Federal de Lavras, Departamento de Ciências Florestais DCF / UFLA Lavras-Brasil

\section{Recebido em: 08/09/2015 - Aprovado em: 14/11/2015 - Publicado em: 01/12/2015} DOI: http://dx.doi.org/10.18677/Enciclopedia_Biosfera_2015_212

\section{RESUMO}

Objetivou-se avaliar e aplicar as redes neurais artificias (RNA) para estimar o diâmetro (di) ao longo do fuste (hi) em um plantio de Eucalyptus sp., e com isso comparar com o método de regressão linear por um polinômio do quinto grau (PQG). Foram cubadas 74 árvores pelo método absoluto e destrutivo, coletando diâmetros (di) a várias alturas (hi). Para realizar a modelagem de predição dos diâmetros, a base de dados foi dividida em um conjunto de treinamento e outro de teste. O PQG foi ajustado por meio do software estatístico $R$ considerando o método dos mínimos quadrados ordinários como procedimento de ajuste. As variáveis utilizadas para estimar os diâmetros (di) das árvores pelo método do PQG foram: Dap (diâmetro a $1,30 \mathrm{~m}$ ), di, hi e Ht (altura total). A RNA do tipo perceptron de múltiplas camadas foi implementada no software Scilab com o auxílio do ANN toolbox. As variáveis utilizadas para o treinamento da RNA foram obtidas por meio de combinações com diferentes operações matemáticas nos dados de Dap, hi e Ht. As estatísticas MAPE, MAD, MSD, RSME (\%) foram aplicadas nos dados estimados com a finalidade de analisar os desvios frente aos dados observados e realizar a comparação entre os métodos utilizados. Considerando uma comparação aplicada dos métodos, foi calculado o volume e a quantificação do sortimento por árvore, usando como base as estimativas geradas. A RNA em geral apresentou boas estatísticas e um melhor gráfico residual. Conclui-se que ambas as metodologias mostraram-se eficientes para alcançar os objetivos propostos, assim as RNA podem ser consideradas como uma boa alternativa de uso e aplicação.

PALAVRAS-CHAVE: Afilamento, Inteligência Artificial. Manejo florestal 


\title{
FORECAST DIAMETERS ALONG THE STEM BY ARTIFICIAL NEURAL NETWORKS
}

\begin{abstract}
This study aimed apply and evaluate the artificial neural networks (ANN) to estimate the diameter (di) along the stem (hi) in a plantation of Eucalyptus sp., and after compare with the linear regression method for the fifth polynomial degree (QGP). Seventy four trees were cubed by the absolute and destructive method. The diameters (di) were collect at different heights (hi). To model the prediction of diameters, was necessary divided the database into a training set and other for test We adjusted the QGP and used the statistical software $R$ considering the method of ordinary least squares as adjustment procedures. The variables used to model by regression QPG were: Dap (diameter $1,30 \mathrm{~m}$ ), di, hi and $\mathrm{Ht}$ (overall height). The ANN perceptron type multilayer was implemented in Scilab software with the help of ANN toolbox. The variables used for the training of ANN were obtained by an combinations with different mathematical operations on data Dap, hi and Ht.The statistics, MAP,MAD, MSD, RSME (\%) were applied on the estimated data for the purpose of analyzing the deviations compared to the observed data and compare the methods used. Considering a apply comparison of the methods, the volume and the quantification were calculated for individual trees, using the estimates data. The RNA showed good statistics and a better residual plot. We conclude that both methods were effective to achieve the proposed objectives. The RNA can be considered as a good alternative to the use and application.
\end{abstract}

KEYWORDS: Forestry, Taper, Artificial Intelligence

\section{INTRODUÇÃO}

Atualmente o conceito de floresta de múltiplos produtos é bastante difundido e, provavelmente é a opção que apresenta maior possibilidade de remuneração do produto advindo de povoamentos florestais (SOARES et al. 2003). Seguindo a abordagem do mesmo autor, percebe-se que há uma tendência de modernização entre as empresas florestais brasileiras quanto à sua forma administrativa, pois vêm passando a adotar tecnologias que possibilitam seu desenvolvimento e maior retorno financeiro.

Nesse contexto, as técnicas que possibilitam a quantificação e qualificação dos produtos florestais mostram-se necessárias ao setor, e para isso, os modelos de afilamento (taper) apresentam-se como uma boa alternativa para determinação do volume total e comercial de madeira em qualquer diâmetro ou altura especificada (LEITE et al. 2006). GUIMARÃES, et al. (1992) afirmam que esta técnica já é bastante difundida nos países que apresentam uma maior tradição florestal e dentre as vantagens em utilizá-la, destaca-se a sua importância frente à decisão do manejo e planejamento florestal, o que diretamente implica na maximização do aproveitamento da madeira produzida.

O ponto mais importante na quantificação dos diâmetros é a possibilidade de previsão do sortimento. Este tipo de inferência é empregado desde o inventário até o planejamento florestal. A quantificação tem como caráter a possibilidade de previsão da receita auferida, quando a empresa apresenta opções de venda de produtos discriminados (toras) por especificações técnicas. Nesse sentido, há a possibilidade de se explorar uma diversificação de produtos a serem extraídos do plantio.

Dessa maneira, os modelos polinomiais são frequentemente utilizados no meio florestal e caracterizam-se por um ajuste de regressão, onde a variável 
dependente é expressa pela razão entre o diâmetro (di) tomado ao longo do fuste e o diâmetro a 1,30 m (Dap), ou seja, (di/Dap). Já as variáveis independentes caracterizam-se pela razão entre a altura (hi) tomada ao longo do fuste e a altura total $(\mathrm{Ht})$ elevada a uma potência (pi), ou seja, $(\mathrm{hi} / \mathrm{Ht})^{\wedge}{ }^{\mathrm{pi}}$. No caso do polinômio do $5^{\circ}$ grau, desenvolvido por SCHOPFER (1966), essas potências são 1, 2, 3, 4 e 5, (FISCHER, et al. 2001). Este modelo foi considerado acurado para estimativa dos diâmetros e volume dos sortimentos para Eucalyptus grandis conforme os trabalhos de SCHNEIDER et al. (1996), MÜLLER (2005) e MENDONÇA (2007) citado por (FAVALESSA, 2011).

Entretanto, uma abordagem alternativa para a modelagem da função de afilamento (taper) consiste no uso de redes neurais artificiais (RNA). Segundo BINOTI (2013), a utilização de redes neurais artificiais (RNA) têm-se apresentado como uma alternativa promissora em relação às técnicas de regressão no manejo dos recursos florestais. O autor cita diversos trabalhos desenvolvidos visando à adaptação e parametrização da rede para diversas situações, dentre elas: estimação do volume de árvores (SILVA et al.,2009), crescimento e produção (BINOTI, 2010), taper (DIAMANTOPOULOU, 2005; LEITE et al., 2010), modelos hipsométricos (BINOTI et al., 2012a), modelagem da distribuição diamétrica (BINOTI et al., 2012b) e também seu trabalho sobre estimação de altura para povoamentos de Eucaliptos, ( BINOTI, 2013).

Segundo HAYKIN, (2001) citado por BINOTI (2013) a estrutura maciça e paralelamente distribuída (camadas); habilidade de aprendizagem e generalização; tolerância a falhas e ruídos; modelagem de diversas variáveis e relações não lineares; analogia neurobiológica e modelagem com variáveis categóricas (qualitativas) e numéricas (quantitativas) são fatores que influenciam positivamente no desempenho das redes neurais artificiais.

Assim, no presente estudo, objetivou-se aumentar a precisão das estimativas diamétricas ao longo do fuste das árvores, tendo como métodos o uso das redes neurais artificiais (RNA) e um modelo de regressão linear múltiplo (polinômio do quinto grau) em um povoamento comercial de Eucalyptus dunni. De forma complementar, buscou-se comparar a quantificação do volume individual das árvores e do sortimento de madeira a partir dos diâmetros estimados.

\section{MATERIAL E MÉTODOS}

\section{Base de dados}

A área do estudo compreende um plantio comercial clonal da espécie Eucaliptus dunni, cujo plantio encontra-se aos 8 anos de idade. No povoamento, foram cubadas 74 árvores pelo método destrutivo e de forma absoluta, produzindo um total de 820 diâmetros (di) à diferentes alturas relativas (hi). Estes registros representam medições diamétricas ao longo do fuste comercial das árvores plantadas.

Para realizar a modelagem de predição dos diâmetros, a base de dados formada pelos registros supracitados foi dividida em dois conjuntos de dados independentes: conjunto de treinamento e conjunto de teste. A função do conjunto de treinamento foi de realizar o aprendizado para a rede e a estimativa dos parâmetros do modelo. Já o conjunto de teste foi utilizado para avaliar a capacidade de generalização das redes e do modelo de regressão, ou seja, avaliar a capacidade das estimativas geradas a partir de dados desconhecidos. 
Logo, para formar o conjunto de treinamento, foram selecionadas 52 árvores (aproximadamente $70 \%$ do total de árvores), as quais corresponderam a 568 diâmetros (di) à diferentes alturas relativas (hi). Já o conjunto de teste correspondeu às demais 22 árvores, que apresentaram 252 diâmetros (di) para cada altura relativa (hi) a serem estimados. Esta lógica foi aplicada em ambos os métodos de predição para os critérios comparativos.

\section{Métodos de predição}

\section{Polinômio do quinto grau (PQG)}

A base de treinamento foi ajustada pelo modelo estatístico de regressão do polinômio do quinto grau (Equação 1) por meio do software estatístico R (R CORE TEAM, 2013), considerando o método dos mínimos quadrados ordinários como o procedimento de ajustamento.

$$
\frac{\mathrm{d}_{\mathrm{i}}}{\operatorname{Dap}_{\mathrm{i}}}=\beta_{0}+\beta_{1}\left(\frac{\mathrm{h}_{\mathrm{i}}}{\mathrm{ht}_{\mathrm{i}}}\right)^{1}+\beta_{2}\left(\frac{\mathrm{h}_{\mathrm{i}}}{\mathrm{ht}_{\mathrm{i}}}\right)^{2}+\beta_{3}\left(\frac{\mathrm{h}_{\mathrm{i}}}{\mathrm{ht}_{\mathrm{i}}}\right)^{3}+\beta_{4}\left(\frac{\mathrm{h}_{\mathrm{i}}}{\mathrm{ht}_{\mathrm{i}}}\right)^{4}+\beta_{5}\left(\frac{\mathrm{h}_{\mathrm{i}}}{\mathrm{ht}_{\mathrm{i}}}\right)^{5}+\varepsilon_{\mathrm{i}}
$$

Em que: Dapi-diâmetro a altura de 1,30 metros do solo da arvore $i ; d_{i}$ diâmetro da árvore $i$ obtido na respectiva altura $h i$ ao longo do fuste comercial, $h_{i}$ altura de medição na posição $i$ ao longo do fuste da arvore e $h_{i}$ - altura total da árvore $i$.

\section{Redes Neurais Artificiais (RNA)}

As redes neurais artificiais (RNA) foram criadas com base na aprendizagem de sistemas biológicos, representando uma rede complexa de neurônios interconectados. Estes neurônios, do tipo Perceptron (ROSENBLAT, 1958), recebem os valores de cada atributo $\left(x_{i}\right)$ bem como o valor de saída esperado. Os valores de entrada recebem um peso aleatório, $w_{i}$, que determina a contribuição da entrada $x_{i}$ na saída do Perceptron. Segundo CARVALHO (2015), o somatório do produto destes pesos $\left(w_{i}\right)$ e seus respectivos atributos $\left(x_{i}\right)$ é o valor de entrada para a função de ativação, responsável pela classificação final do neurônio. Esta função, que pode ser limiar, sigmoidal, hiperbólica ou semilinear, restringe a amplitude de saída do neurônio e aplica a não linearidade do modelo. $O$ aprendizado do neurônio consiste em ajustar os pesos de cada entrada para que o valor de saída obtido seja igual ao valor dado pela amostra de treinamento, no sentido de minimizar o erro.

Nesse sentido, para o presente estudo a rede neural artificial do tipo perceptron de múltiplas camadas, foi implementada no software Scilab, versão 5.5.1, com o auxílio do $A N N$ toolbox. Para o treinamento e validação da rede, os dados de entrada e saída foram normalizados em um intervalo de 0 a 1 utilizando a razão pelo valor máximo de cada variável.

Com o intuito de aumentar a precisão das redes, diversas transformações matemáticas foram realizadas com as variáveis DAP, HT e hi. Mediante aos diversos testes preliminares, o conjunto de variáveis de entrada utilizadas na estimação dos diâmetros, foi constituído por: $H T, \sqrt{h i}, \ln (H T), \ln (D A P) * \ln (h i), \sqrt{D A P} * \ln (h i), \sqrt{H T} * \ln (D A P)$. 
Foram realizados testes preliminares avaliando diferentes valores do termo Momentum, taxa de aprendizagem e número de neurônios em cada camada oculta. A rede neural foi estruturada com duas camadas ocultas de processamento, com 6 neurônios na primeira camada oculta e 1 neurônio na segunda camada. A função de ativação adotada para todos os neurônios foi a do tipo sigmoidal. Os parâmetros de aprendizagem selecionados para este trabalho foram: a) termo Momentum 0,9 e b) taxa de aprendizagem de 0,07 . A estrutura da rede utilizada neste trabalho pode ser visualizada na Figura 1.

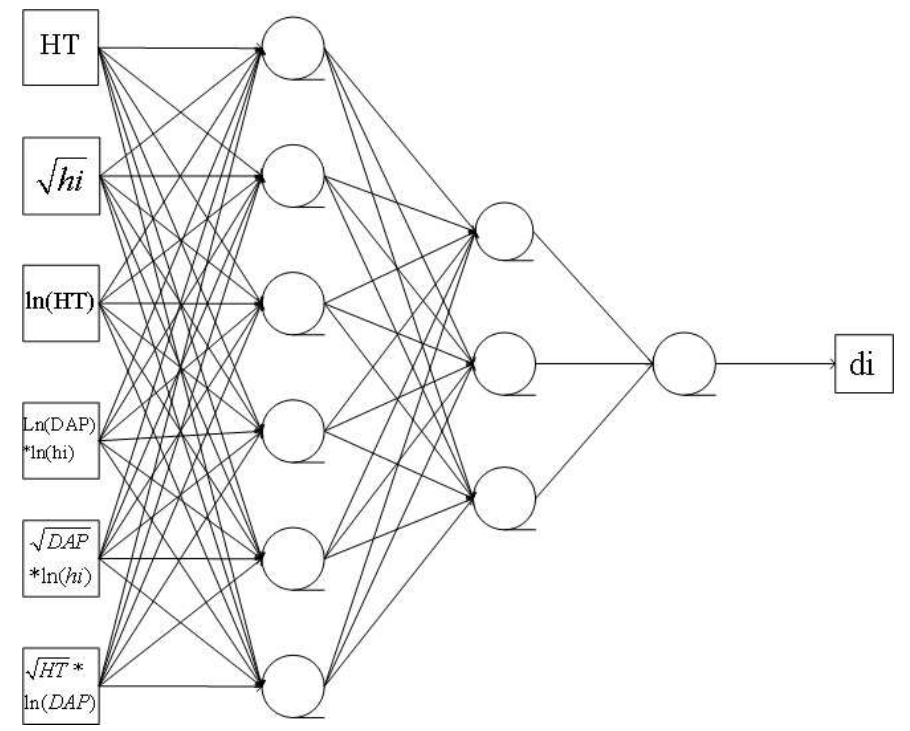

FIGURA 1 Representação da estrutura da rede neural utilizada neste trabalho, onde: DAP - diâmetro à altura do peito; ht - altura total da árvore; hi altura a ser estimado o diâmetro; dicc diâmetro correspondente a hi

O treinamento da rede foi realizado de forma supervisionada, ou seja, foram apresentados, no conjunto de treinamento, os valores de entrada e saída esperada. O método utilizado para 0 aprendizado da rede é o de retropropagação (backpropagation), o qual consiste na mudança interativa dos pesos sinápticos a fim de minimizar os erros de classificação para as próximas iterações. Na figura 2 é possível visualizar o comportamento do erro quadrático médio para o conjunto de dados de treinamento e de teste (normalizados) durante o treinamento da rede. Pelo gráfico é possível compreender que o erro fica constante a partir de 380 iterações, no entanto o critério de parada adotado neste trabalho foi de 500 iterações. 


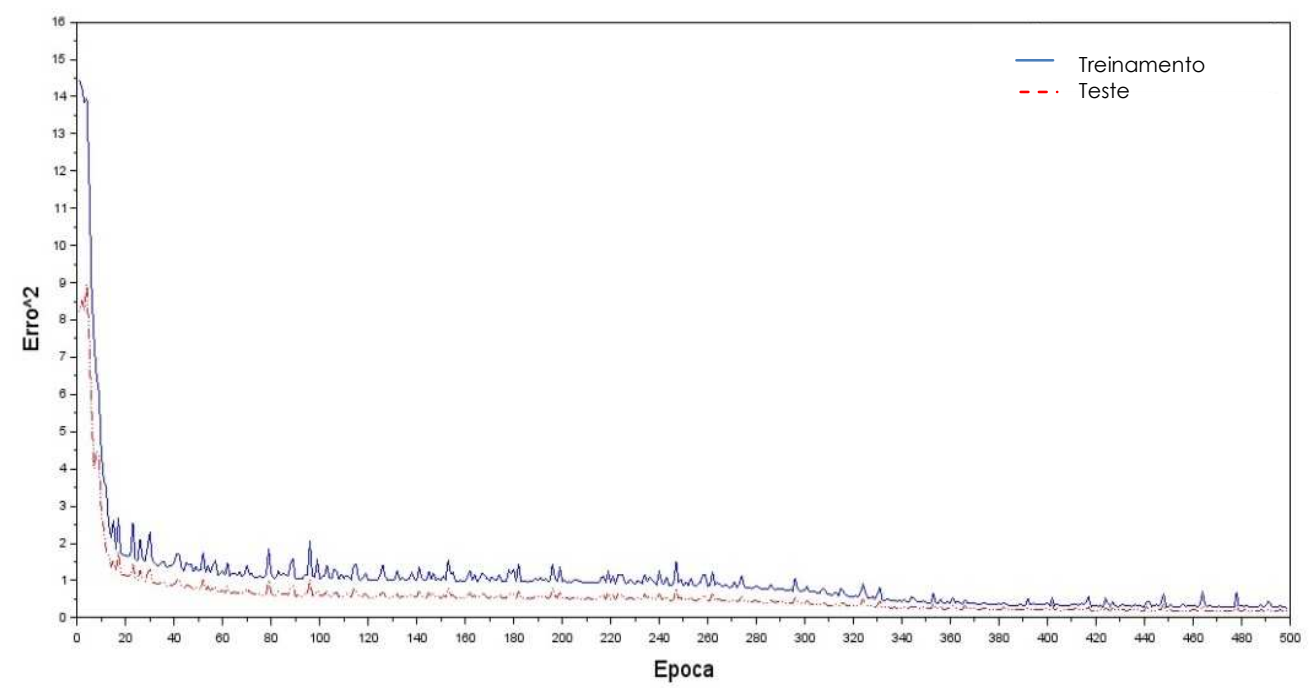

FIGURA 2 Gráfico do erro quadrático médio normalizado obtido para os conjuntos de treinamento e de teste durante o treinamento da rede

\section{Análise comparativa entre métodos}

Devido à natureza diversa dos princípios dos métodos empregados, optou-se por trabalhar com a análise dos desvios, sendo a diferença entre o dado observado e o predito. Nesse sentido as estatísticas MAPE (Mean Absolute Percentage Error), MAD (Mean Absolute Deviation) e MSD (Mean Squared Deviations) foram aplicadas, indicando que os menores valores de suas estatísticas representam os melhores resultados, ou seja, melhor o modelo se adapta aos dados. A média do erro percentual absoluto (MAPE) manifesta a rigor como uma percentagem do erro. Como esse número é percentual, pode ser mais fácil de entendê-lo em relação às outras estatísticas. Já o desvio médio absoluto (MAD), manifesta a precisão nas mesmas unidades que estão os dados, o que ajuda a conceituar a quantidade de erros. E por último, a média do quadrado do desvio (MSD) é uma medida utilizada para precisão dos valores da série, (KUMAR, 2009). $(4)$,

O calculo das estatísticas empregadas podem ser observadas em (2), (3) e

$$
\begin{aligned}
& \text { MAPE }=\frac{\sum_{i=1}^{n}\left(\frac{y_{i}-\hat{y}_{i}}{y_{i}}\right) 100}{n} \\
& M A D=\frac{\sum_{i=1}^{n}\left|y_{i}-\hat{y}_{i}\right|}{n} \\
& M S D=\frac{\sum_{i=1}^{n}\left|y_{i}-\hat{y}_{i}\right|^{2}}{n}
\end{aligned}
$$


Em que $\mathrm{n}=$ número total de observações da base de dados da cubagem; $\mathrm{y}_{\mathrm{i}}=$ valor real obtido referente a $i$-ésima observação da base de dados; e $\hat{y}_{i}=$ valor predito referente a $i$-ésima observação da base de dados.

Para realizar comparações com outras aplicações de redes no setor florestal, foi calculada a raiz quadrada do erro médio - RMSE (\%) (5) para os dois métodos de predição utilizados, em que $y_{i}$ são os diâmetros observados, $\hat{y}_{i}$ os diâmetros estimados, $\overline{y_{i}}$ a média dos diâmetros totais observados e $\mathrm{n}$ o número total de observações.

$$
\operatorname{RMSE}(\%)=\frac{100}{\overline{y_{i}}} \sqrt{\frac{\sum_{i=1}^{n}\left(\mathrm{y}_{i}-\bar{y}_{i}\right)^{2}}{n}}
$$

\section{Aplicações diretas das estimativas}

Após a análise dos desvios frente aos dados observados, considerou-se uma comparação aplicada dos métodos. Assim, para a mesma base de conjunto teste (22 árvores), foi realizado o cálculo do volume aproximado das árvores a cada seção geométrica definida pelos pares $d_{i}$ e $h_{i}$ utilizando a base de dados real de campo. Neste caso, optou-se por utilizar o método de Smalian, conforme a Equação (6).

$$
\mathrm{v}=\sum_{\mathrm{i}=1}^{\mathrm{N}}\left(\frac{\mathrm{g} 1_{\mathrm{i}}+\mathrm{g} 2_{\mathrm{i}}}{2}\right) \cdot \mathrm{L}+\frac{1}{3} \mathrm{gf}(\mathrm{Ht}-\mathrm{hf})
$$

Em que: $v$ - volume total da árvore; g1i - área basal seção 1; g2i - área basal seção 2; L- comprimento da seção; gf - área basal da última seção; Ht- altura total e hf - comprimento da última seção, onde o último termo da expressão representa o volume obtido por um cone, ou o topo da árvore.

Com os dados de diâmetros estimados pelos dois métodos (RN e PLQ), foi realizado o volume aproximado (Smalian) de cada árvore e comparou-se com o volume real anteriormente calculado.

Foi aplicado o teste estatístico t de Student com a finalidade de verificar se os volumes obtidos a partir dos diâmetros estimados diferenciam-se dos dados observados, com um nível de $5 \%$ de probabilidade. Assim, as hipóteses nulas testadas foram a não diferença significativa entre os métodos e o real, de forma a verificar se é possível a utilização das redes neurais artificiais como método de predição dos diâmetros ao longo do fuste de uma árvore, sem a necessidade de uso de uma função de afilamento. Outra comparação aplicada realizada foi a quantificação do sortimento de madeira por produto especificado (Tabela 1).

TABELA 1 Especificação técnica dos tipos de produtos a serem gerados e comercializados

\begin{tabular}{lcc}
\hline \multicolumn{1}{c}{ Tipo de Produto } & di mín $(\mathbf{c m})$ & Comprimento $(\mathbf{m})$ \\
\hline 1- Laminação & 30,0 & 2,4 \\
2- Serraria & 25,0 & 4,0 \\
3- Pallets & 18,0 & 2,8 \\
4- Celulose & 7,0 & 2,6 \\
\hline
\end{tabular}


Em que: di mín: representa o diâmetro mínimo de ponta da tora conforme especificação do tipo de produto.

A partir dos parâmetros ajustados do PQG e do aprendizado da RNA, foi possível estimar o diâmetro para qualquer altura, assim, utilizou-se as alturas estabelecidas por cada produto.

\section{RESULTADOS E DISCUSSÃO}

A princípio, ao se analisar os valores das medidas estatísticas de comparação entre os métodos, pode-se observar que ambos apresentam um desempenho satisfatório. O resultado indica que é possível estimar os diâmetros ao longo do fuste com certa precisão e confiança (Tabela 2). Pode-se observar que a RNA apresentou os menores valores em duas das estatísticas aplicadas, podendo ser mais precisa se comparada ao polinômio do quinto grau, um método tradicionalmente aplicado no setor florestal brasileiro.

TABELA 2 Resultados das medidas estatísticas obtidas pelos métodos testados

\begin{tabular}{cccc}
\hline Modelo & MAD & MAPE (\%) & MSD \\
\hline PQG & 0,7001 & 5,9467 & 0,9832 \\
RNA & 0,7048 & 5,0158 & 0,9597 \\
\hline
\end{tabular}

De forma a confirmar os resultados das estatísticas supracitadas, a partir dos resultados do quadrado do erro médio - RMSE (\%) foi possível verificar que novamente a RNA mostrou-se mais precisa, apesar de ter obtido valores próximos ao do PQG, sendo $6,67 \%$ e $6,84 \%$ respectivamente.

BINOTI et al., (2014) aplicaram o modelo tradicional de regressão (Schumacher Hall) para estimar volume individual de árvores de eucalipto spp., comparando com diferentes configurações de RNA. O modelo de regressão apresentou um RMSE (\%) de 7,28 enquanto a rede menor que 1. BINOTI et al., (2013) aplicaram as RNA para estimar a altura de povoamentos equiâneos de eucalipto e obtiveram um RMSE (\%) variando de 3 a 5 . No presente estudo, a estimativa do diâmetro a diversas alturas apresentou um resultado satisfatório para ambos os métodos de estimativa. Entretanto, a RNA retratou menores valores e uma menor dispersão dos resíduos, Figura 3.

As estimativas diamétricas (di) nas extremidades das árvores (hi) não apresentaram os melhores resultados, como pode ser verificado na Figura 3. O modelo do PQG apresentou maiores discrepâncias nos menores valores de diâmetros estimados quando comparado à RNA.
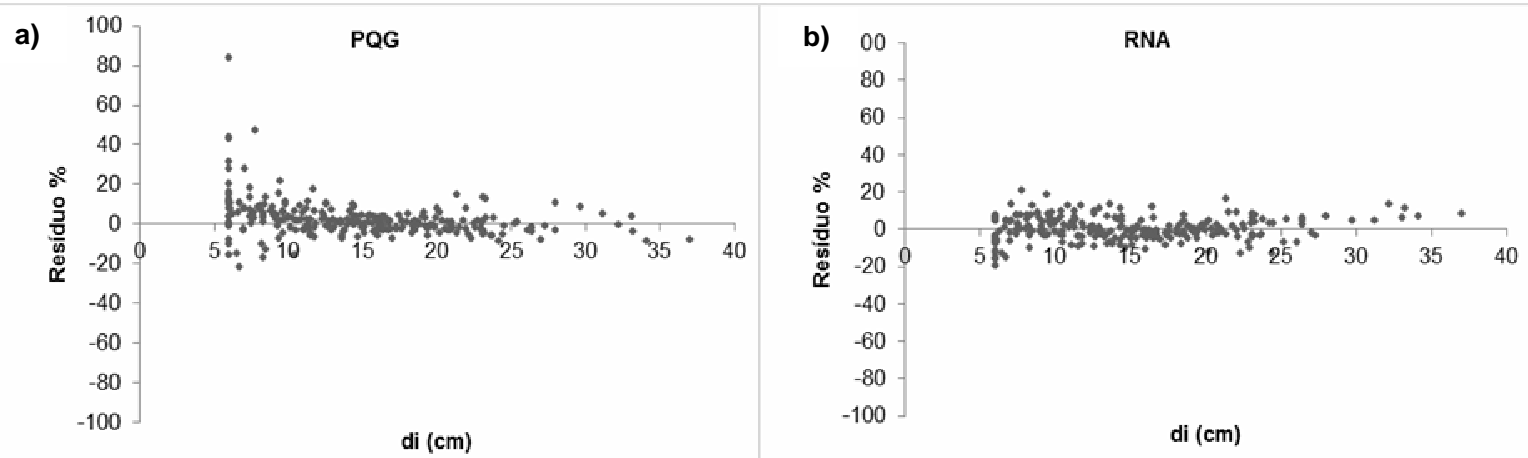
FIGURA 3: Comportamento do gráfico de resíduo $\left(\mathrm{y}_{\mathrm{i}}-\hat{\mathrm{y}}_{\mathrm{i}}\right)$ ao longo do fuste das árvores, sendo (a) observado e PQG e (b) observado e RNA. Sendo di $(\mathrm{cm}) \mathrm{o}$ diâmetro observado.

BINOTI et al., (2014), ao avaliarem graficamente os resultados, observaram reduzida diferença nas estimativas das RNA ao se comparar com modelo de Schumacher e Hall, contudo, as RNA apresentaram um melhor resultado visualmente. De forma geral, pode-se optar pela escolha da RNA para o presente estudo, já que a mesma apresentou um comportamento mais uniforme dos resíduos.

A partir dos dados estimados, pôde ser calculado o volume individual das árvores pelo método de Smalian. Observou-se que volume calculado a partir das estimativas do PQG apresentou um resultado um pouco mais próximo do real.(Tabela 3). No entanto, para validar este resultado, foi aplicado o teste estatístico t de Student, e verificou-se que os volumes foram estatisticamente iguais a 5\% de significância, entre o observado e a RNA, bem como entre o observado e o PQG. As médias pelos dois métodos foram muito próximas entre si e próximas ao observado $\left(0,2832 \mathrm{~m}^{3}\right)$. Indiretamente pode-se inferir que os diâmetros estimados $\left(\hat{\mathrm{d}}_{\mathrm{i}}\right)$ pela regressão ou pela rede são estatisticamente semelhantes, e com isso seu volume de forma análoga.

TABELA 3 Volume total considerando diferentes modelos

\begin{tabular}{cccc}
\hline Método & Volume $\left(\mathbf{m}^{3}\right)$ & $\mathbf{t}$ calculado & t tabelado \\
\hline Real & 0,2832 & - & 2,0796 \\
PQG & 0,2813 & $-0,0440$ & \\
RNA & 0,2793 & $-0,1067$ & \\
\hline
\end{tabular}

A Tabela 4 apresenta o resultado da quantificação do sortimento obtido por tipo de produto, cujo valor foi oriundo das 22 árvores cubadas como teste.

TABELA 4 Sortimento de produtos gerados pelos métodos RNA e PQG para as árvores

\begin{tabular}{ccccccc}
\hline Método & \multicolumn{4}{c}{ Número de produtos } & $\begin{array}{c}\text { Número } \\
\text { Total toras }\end{array}$ & $\begin{array}{c}\text { Resíduo } \\
\left(\mathbf{m}^{\mathbf{3}}\right)\end{array}$ \\
\cline { 2 - 5 } & $\mathbf{1}$ & $\mathbf{2}$ & $\mathbf{3}$ & $\mathbf{4}$ & 103 & 176,5 \\
PQG & 1 & 1 & 15 & 86 & 111 & 154,3 \\
RNA & 0 & 1 & 21 & 89 & 111 \\
\hline
\end{tabular}

Pôde-se observar que o número total de toras por tipo de produto foi diferente entre os métodos testados. Não foi gerada nenhuma tora para laminação (1) via RNA, bem como grandes diferenças entre o produto pallets (3), pelos métodos testados. A única semelhança foi o número de toras para serraria (2) e valores próximos para o produto celulose (4). A explicação para o fato está na sensibilidade do método de contagem de toras por produtos, já que o fator técnico diâmetro mínimo de ponta $(\mathrm{cm})$ oriundo de estimativa, é o que define ou não a sua existência. Isso indica que pequenas alterações para baixo ou para cima das estimativas dos diâmetros, muda consideravelmente o número de toras ao término dos cálculos.

Ao avaliar o número de toras total aproveitadas para as 22 árvores, pode-se observar que as RNA proporcionaram um melhor aproveitamento do fuste das árvores e um menor valor residual $\left(\mathrm{m}^{3}\right)$. $\mathrm{O}$ uso das funções de afilamento são usualmente aplicadas no setor florestal brasileiro para tomada de decisão, no 
entanto, como a RNA apresentou em média, pelas estatísticas avaliadas, um bom desempenho e um melhor gráfico residual em relação ao PQG, sua escolha para utilização torna-se plausível.

\section{CONCLUSÕES}

A RNA apresentou, em média, pelas estatísticas avaliadas, um melhor desempenho quando comparado ao modelo do PQG. Contudo, o volume individual quantificado pelas estimativas não diferiram estatisticamente entre si, e os valores absolutos quantificados pelo sortimento foram diferentes para os métodos, porém não prejudica o uso dos mesmos. Portanto, pode-se afirmar que a RNA foi eficiente para a estimação dos diâmetros no povoamento de Eucaliptus dunni mostrando-se como uma boa alternativa de uso e aplicação.

\section{REFERÊNCIAS}

BINOTI, M. L. M. S; Redes neurais artificiais para prognose da produção de povoamentos não desbastados de eucalipto. 2010. 54f. Dissertação (Mestrado em Ciência Florestal) - Universidade Federal de Viçosa, Viçosa, MG, 2010.

BINOTI, D. H. B.; BINOTI, M.L.M.S.; GARCIA, H.G.; SILVA, A. Redução dos custos em inventário de povoamentos equiâneos utilizando redes neurais artificiais. Agrária, v. 8, p. 125-129, 2012a.

BINOTI, D. H. B.; BINOTI, M.L.M.S.; LEITE, H.G.; SILVA, A.; SANTOS, A.C.A. Modelagem da distribuição diamétrica em povoamentos de eucalipto submetidos a desbaste utilizando autômatos celulares. Revista Árvore, v.36, n.5, p.931-939, 2012b.

BINOTI, M.L.M.S.; BINOTI, D.H.B.; LEITE, H.G. Aplicação de redes neurais artificiais para estimação da altura de povoamentos equiâneos de eucalipto. Revista Árvore, Viçosa-MG, v.37, n.4, p.639-645, 2013.

BINOTI, D. H. B.; BINOTI, M. L. M. S.; LEITE, H, G. Configuração de redes neurais artificiais para estimação do volume de árvores. Revista Ciência da Madeira (Brazilian Journal of Wood Science), v. 5, n. 1, p. DOI: 10.12953/2177-6830. v05n01a06, 2014.

BRACELPA. Disponível <http://bracelpa.org.br/bra2/?q=node/136>. Acesso em: 10 abril 2015.

CARVALHO, M. C. Modelagem preditiva da distribuição potencial de espécies arbóreas na bacia hidrográfica do Rio Grande. Dissertação (Mestrado em Ciências Florestais) - Universidade Federal de Lavras, 2015.

FAVALESSA, C.M.C. Funções de afilamento segmentadas e não segmentadas para povoamentos de Tectona grandis L. f. no município de Rosário Oeste-MT. 2011.

FISCHER, F.; SCOLFORO, J.R.S; JÚNIOR, F.W.A.; MELLO, J.M.; MAESTRI, R. Exatidão dos modelos polinomiais não-segmentados e das razões entre volumes 
para representar o perfil do tronco de Pinus taeda. Ciência Florestal, v. 11, n. 1, p. 167-188, 2001.

GUIMARÃES, D. P.; LEITE, H. G. Um novo modelo para descrever o perfil do tronco. Revista Árvore, v.16, n.2, p.170-180, 1992.

HAYKIN, S. Redes neurais: princípios e prática. Porto Alegre: 2001. 900p.

IPEF. Disponível <http://www.ipef.br/identificacao/cief/especies/dunnii.asp>. Acesso em: 10 abril 2015.

KUMAR, S. Quantitative Methods. Gyan Publishing House, 2009.

LEITE, H. G.; GAMA. J. R,V.; CRUZ. J. P.; SOUZA. A.L. Função de afilamento para virola surinamensis (ROLL.) WARB. Revista Árvore, Viçosa-MG, v.30, n.1, p.99106, 2006.

MENDONÇA, A. R.; SILVA, G. F.; OLIVEIRA, J. T. S.; NOGUEIRA, G. S.; ASSIS, A. L. Avaliação de funções de afilamento visando a otimização dos fustes de Eucalyptus sp.para multiprodutos. Cerne, Lavras, v.13, p.71-82, 2007.

MÜLLER, I.; FINGER, C. A. G.; SCHENEIDER, P. R. Forma do tronco e sortimentos de Madeira de Eucalyptus grandis Hill ex Maiden, na região sudeste do estado do Rio Grande do Sul. Ciência Florestal, v.15, n.3, p.293-305. Santa Maria. 2005.

R DEVELOPMENT CORE TEAM. R: a language and environment for statistical computing. Vienna: R Foundation for Statistical Computing, 2013. Disponível em: < http://www.R-project.org>.

SCHNEIDER, P. R.; FINGER, C. A. G.; KELIN, J. E. M.; TOTTI, J. A.; BAZZO, J. L. Forma de fuste e sortimentos de madeira de Eucalyptus grandis Maiden para o estado do Rio Grande do Sul. Ciência Florestal, v.6, n.1, p.79-88, 1996.

SCOLFORO, J.R.S.; FIGUEIREDO FILHO, A. Biometria florestal: medição e volumetria de árvores. Lavras: Universidade Federal de Lavras / Fundação de Apoio ao Ensino, Pesquisa e Extensão. 1998. 310p

SOARES, T. S.; VALE, A. B.; LEITE, H. G.; MACHADO C. C. Otimização de multiprodutos em povoamentos florestais. Revista Árvore, v.27, n.6, p.811-820, 2003. 